\title{
Liposomes Incorporating Transferrin and Stearic Acid-modified Octa-arginine for siRNA Delivery
}

\author{
DONGSHENG YANG ${ }^{1,2}$, XUEWEI YANG ${ }^{3}$, ROBERT J. LEE ${ }^{3,4}$, SONGCAI LIU $^{1}$ and JING XIE ${ }^{3}$ \\ ${ }^{1}$ College of Animal Science and 3College of Life Sciences, Jilin University, Changchun, P.R. China; \\ ${ }^{2}$ Department of Chemistry and Pharmacy, Zhuhai College of Jilin University, Zhuhai, P.R. China; \\ ${ }^{4}$ Division of Pharmaceutics, College of Pharmacy, The Ohio State University, Columbus, OH, U.S.A.
}

\begin{abstract}
Liposomes incorporating stearic acid-modified octa-arginine (StA-R8) and conjugated to transferrin (Tf) were synthesized and evaluated for delivery of small interfering RNA (siRNA) against survivin. Characteristics, cytotoxicity, cellular uptake and biological activity of liposomes complexed to survivin siRNA were investigated. Tf-conjugated liposomes were shown to have reduced cytotoxicity and improved delivery efficiency for siRNA into cancer cells compared to non-conjugated StA-R8 liposomes. These data suggest that Tf-conjugated StA-R8 liposomes are promising vehicles for siRNA delivery in cancer therapy.
\end{abstract}

Cell-penetrating peptides (CPPs) are able to be internalized by mammalian, plant and bacterial cells and to facilitate delivery of molecules with biological activity across the cell membrane (1-3). Many CPPs have been reported, including HIV-Tat (4), penetratin (5), transportan (6) and octa-arginine (R8) (7). R8, is highly cationic and can interact with the plasma membrane and facilitate membrane translocation (8).

Non-viral vectors can be used for delivery of small interfering RNA (siRNA) $(9,10)$. These include liposomes $(11,12)$, polymers $(13)$, and polypeptides (14). Liposomes have difficulty crossing the cellular membrane, which greatly limits their applications in vitro and in vivo. Incorporation of CPPs into liposomes is a strategy to improve membrane translocation (15-17).

Correspondence to: Jing Xie, College of Life Sciences, Jilin University, No.2699, Qianjin St., Changchun, Jilin 130012, P.R. China. Tel: +86 43185168646, Fax: +86 43185168637, e-mail: xiejing@jlu.edu.cn; or Songcai Liu, College of Animal Science, Jilin University, No.5333, Xi'an Ave., Changchun, Jilin 130062, P.R. China. Tel: +86 43185168646, Fax: +86 43185168637, e-mail: songcailiu@jluhp.edu.cn

Key Words: Cell-penetrating peptide, transferrin, survivin, liposomes, cancer.
The transferrin (Tf) receptor is a glycoprotein expressed on the surface of many tumor cells (18). Tf receptor mediates endocytosis of $\mathrm{Tf}$ and $\mathrm{Tf}$ conjugates (19). Tf conjugation has been used in targeted delivery to tissues including tumor, endothelial cells and the brain (20).

In this article, we report the synthesis and evaluation of Tf-conjugated liposomes containing stearic acid-modified R8 (TSLP) for delivery of survivin siRNA into cancer cells.

\section{Materials and Methods}

Materials. 2-Chlorotrityl chloride resins and fluorenylmethyloxycarbonyl-L-arginine (Fmoc-Arg) were obtained from JiEr Biochemical Co. (Shanghai, China). Stearic acid (StA; 98.5\%), cholesterol, holo-human Tf, 2-iminothiolane hydrochloride (Traut's reagent) and 3-(4,5-dimethylthiazol-2-yl)-2,5-diphenyltetrazolium bromide (MTT) were purchased from Sigma-Aldrich (St. Louis, MO, USA). Egg phosphatidylcholine (ePC) was purchased from Avanti Polar Lipids (Alabaster, AL, USA). Distearylphosphatidylethanolamine-polyethyleneglycol (M.W. 2,000)-maleimide (DSPEPEG2000-Mal) was purchased from Shanghai Advanced Vehicle Technology Pharmaceutical Ltd. Co. (Shanghai, China). Fetal bovine serum (FBS), Dulbecco's modified Eagle's medium (DMEM) and $0.25 \%(\mathrm{w} / \mathrm{v})$ trypsin were from HyClone (Logan, UT, USA). Anti-survivin siRNA, and 6-carboxyfluorescein (FAM)labeled siRNA were synthesized by Ribo Biochemistry (Guangzhou, China). 4',6-Diamidino-2-phenylindole (DAPI) was purchased from Invitrogen Molecular Probes (Eugene, OR, USA). All other reagents were commercially purchased in reagent-grade.

Synthesis of StA-R8 and Tf-conjugated PEG-DSPE (Tf-PEG-DSPE). StA-R8 was synthesized by the technique of Fmoc solid-phase peptide synthesis on a 2-chlorotrityl chloride resin as reported previously (21, 22 ). The target peptide was then purified and structurally confirmed. Tf-PEG-DSPE was synthesized using a method modified from a previously reported method (23). Briefly, Tf and Traut's reagent were combined at a molar ratio of 1:10 and incubated for $1 \mathrm{~h}$ in dark, and then dialyzed for $2 \mathrm{~h}$ to generate thiolated Tf. Next, thiolated Tf and DSPE-PEG2000-Mal were combined at a molar ratio of 1:10 and incubated overnight in the dark (24).

Preparation of liposomes. An ethanol dilution method was used for the preparation of liposomes. First, StA-R8, ePC and cholesterol 
were dissolved in ethyl alcohol at a molar ratio of 20:35:45. This solution was then injected into HEPES-buffered saline $(\mathrm{pH} 7.4)$ under vortexing at a lipid/HEPES volume ratio of 1:3 to generate StA-R8 liposomes (SLPs). The liposomes were then sonicated for $30 \mathrm{~s}$. SLP/siRNA was synthesized by combining SLPs with antisurvivin siRNA and incubating for $20 \mathrm{~min}$ at room temperature. A post-insertion method was used to prepare TSLPs. For Tf postinsertion, SLP/siRNA were incubated with Tf-PEG-DSPE at $37^{\circ} \mathrm{C}$ for $30 \mathrm{~min}(25)$.

Agarose gel retardation assay. SLPs were complexed with siRNA at different N/P ratios ( with "N" representing positively charged guanidinium group in StA-R8 component of SLP and "P" representing negatively charged phosphates in siRNA) from $0.5: 1$ to $8: 1$. TSLP/siRNA complexes were prepared at an N/P ratio of $6: 1$. Formation of these complexes was confirmed by a gel retardation assay. The samples were incubated at room temperature for $30 \mathrm{~min}$ and then loaded onto $1 \%(\mathrm{w} / \mathrm{v})$ agarose gel in Tris-acetate-EDTA buffer, containing $1 \mu \mathrm{g} / \mathrm{ml}$ ethidium bromide (Bioteke Corporation, Beijing, China). Electrophoresis was performed at $130 \mathrm{~V}$ for $12 \mathrm{~min}$ and the gel was visualized with a UV lamp using a Vilber Lourmat imaging system (Vilber Lourmat, Marnela Vallée, France).

Particle size and zeta potential measurements. The particle size and zeta potential of SLPs, SLP/siRNA and TSLP/siRNA were determined on a Zetasizer Nano ZS 90 (Malvern Instruments, Ltd., Malvern, UK). The measurements were repeated three times and averaged. SLP/siRNA and TSLP/siRNA samples were stored at $4{ }^{\circ} \mathrm{C}$. To evaluate their stability at this temperature, particle sizes on days $0,1,2,4,6,8,10$ and 12 after synthesis were determined.

Cell culture. HeLa and HepG2 cells were cultured in DMEM with $10 \%$ FBS and $1 \%$ antibiotics/antimycotics in a humidified atmosphere containing $5 \% \mathrm{CO}_{2}$ at $37^{\circ} \mathrm{C}$.

Cytotoxicity assay. Cell viability was measured by MTT assay. HeLa and HepG2 cells were seeded in a 96-well plate $\left(1 \times 10^{4}\right.$ cells/well $)$ and cultured for $24 \mathrm{~h}$. Subsequently, StA-R8, SLPs and TSLP at different concentrations were added to the plate and the cells were incubated for $4 \mathrm{~h}$. Then, serum-free medium was replaced with fresh medium containing FBS. After incubating for another $20 \mathrm{~h}, 10 \mu \mathrm{l}$ of MTT stock solution $(5 \mathrm{mg} / \mathrm{ml})$ was added to each well and the plate was incubated for $4 \mathrm{~h}$ at $37^{\circ} \mathrm{C}$. Finally, $100 \mu \mathrm{l} /$ well DMSO was added to dissolve the formazan crystals formed due to MTT reduction by viable cells. The absorbance was then measured at $490 \mathrm{~nm}$ on a Synergy 4 microplate reader from BioTek Instrument, Inc. (Winooski, VT, USA ).

Cellular uptake assay. Cells were seeded in a 24-well plate at $1 \times 10^{5} /$ well. SLP/siRNAFAM or TSLP/siRNA ${ }^{\text {FAM }}$ diluted in $1 \mathrm{ml}$ of serum-free medium was added to cells, which were then incubated for $4 \mathrm{~h}$ in the dark at $37^{\circ} \mathrm{C}$. Then, the cells were washed three times with PBS, harvested and fixed in $4 \%$ para-formaldehyde. Samples were analyzed on a flow cytometer from BD Biosciences (San Jose, CA, USA).

Confocal microscopy. Cells were seeded in a $35-\mathrm{mm}$ glass bottom culture dish at $1.5 \times 10^{5} /$ well. SLP/siRNA FAM or TSLP/siRNAFAM diluted in $1 \mathrm{ml}$ of serum-free medium was added to the cells, which were incubated for $4 \mathrm{~h}$ in dark at $37^{\circ} \mathrm{C}$. Then, the cells were washed

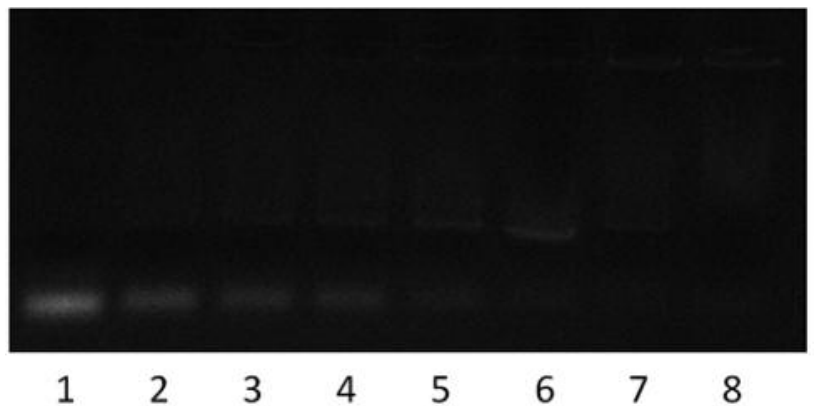

Figure 1. Agarose gel analysis of liposome/siRNA complexes. siRNA complexes were prepared at different N/P ratios. Lane 1, naked siRNA; Lane 2-7: stearic acid-modified octa-arginine (StA-R8)-containing liposome/siRNA complexes at different N/P ratios, 0.5:1 (lane 2), 1:1 (lane 3), 2:1 (lane 4), 4:1 (lane 5), 6:1 (lane 6) and 8:1 (lane 7); 8, transferrin-conjugated liposomes containing StA-R8/siRNA complexes at an N/P ratio of 6:1.

three times with PBS and fixed with $4 \%$ paraformaldehyde/PBS for $20 \mathrm{~min}$. Cellular nuclei were counterstained with DAPI $(2 \mu \mathrm{g} / \mathrm{ml})$ for $3 \mathrm{~min}$ at room temperature and washed with PBS. The cells were then observed on a Zeiss 710 LSMNLO Confocal Microscope from Carl Zeiss (Jena, Germany).

Measurement of survivin protein expression by Western blot. HeLa cells were seeded in a 6 -well plate at $2 \times 10^{5}$ cells/well. SLP/siRNA or TSLP/siRNA diluted in $1 \mathrm{ml}$ of serum-free medium was added and the plate was incubated for $4 \mathrm{~h}$ at $37^{\circ} \mathrm{C}$. The serum-free medium was then replaced with fresh medium containing $10 \%$ FBS. The cells were cultured for another $44 \mathrm{~h}$, washed and harvested. Western blot was used to measure survivin protein expression.

\section{Results}

Formation of SLP/siRNA complexes. In order to evaluate the complexing activity of various liposomes to survivin siRNA, agarose gel electrophoresis was performed. Free survivin siRNA showed a bright band on the gel, which is absent when siRNA was complexed to liposomes. As shown in Figure 1, the first lane is naked siRNA. With increase of charge (N/P) ratio, the brightness of the band was reduced. When the N/P ratio was above $6: 1$, the band almost disappeared, indicating complete complexation of siRNA by the liposomes. The eighth lane in Figure 1 shows that TSLP/siRNA had a good complexation efficiency when the N/P ratio was $6: 1$ and that insertion of Tf had no significant effect on complexation efficiency.

Characterization of liposomes. Liposomes were prepared as described above. Particle size and $\zeta$ potential of SLPs, SLP/siRNA and TSLP/siRNA are shown in Table I. After complexing with siRNA, particle size of SLPs increased and the $\zeta$-potential decreased. Compared to SLP/siRNA, particle size and $\zeta$-potential for TSLP/siRNA changed, which was 


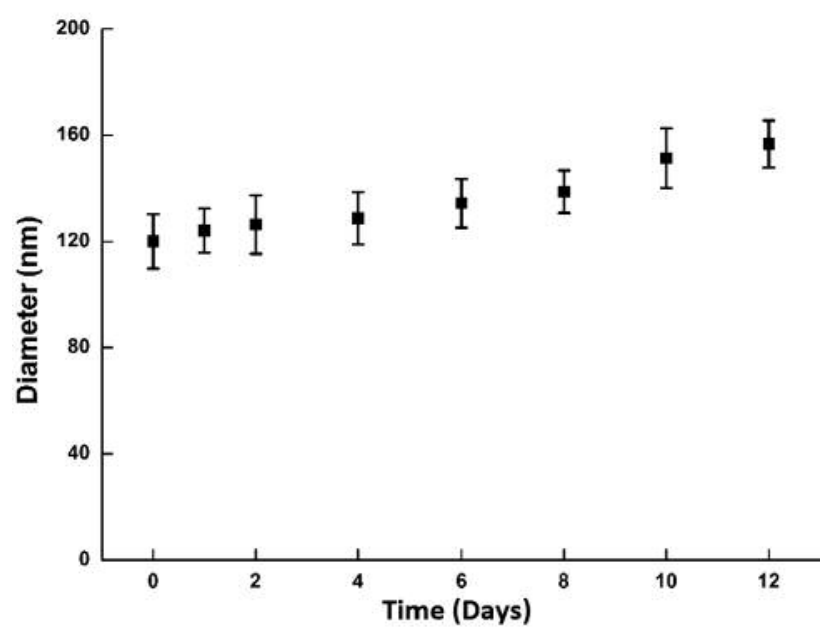

Figure 2. Stability of by particle size measurement.Transferrinconjugated liposomes containing stearic acid-modified octa-arginine complexed with siRNA were synthesized as described in the Materials and Methods and stored at $4^{\circ} \mathrm{C}$. Particle size was measured by dynamic light scattering at different time points.

Table I. Size and $\zeta$-potential of stearic acid-modified octa-arginine (StA$R 8)$-containing liposomes (SLP), SLP/siRNA and transferrin-conjugated liposomes containing StA-R8 (TSLP)/siRNA at $p H$ 7.4. Data are shown as the mean and standard deviation $(n=3)$.

\begin{tabular}{lcc}
\hline Formulation & Average particle size $(\mathrm{nm})$ & $\zeta$ Potential $(\mathrm{mV})$ \\
\hline SLP & $107.1 \pm 3.64$ & $15.1 \pm 3.12$ \\
SLP/siRNA & $120.1 \pm 10.27$ & $7.7 \pm 0.65$ \\
TSLP/siRNA & $148.7 \pm 11.95$ & $4.7 \pm 0.2$ \\
\hline
\end{tabular}

due to the presence of negatively charged Tf. TSLP had good colloidal stability at $4^{\circ} \mathrm{C}$, and the particle size remained below $200 \mathrm{~nm}$ (Figure 2).

Assessment of cytotoxicity. The cytotoxicity of SLPs and TSLP was determined in HeLa and HepG2 cells. Figure 3 shows the effects of StA-R8, SLP and TSLP on cell viability. As shown, at all concentrations of liposomes studied, cell viability in both cell lines was over $85 \%$ compared with the control $(0 \mu \mathrm{g} / \mathrm{ml})$. Free StA-R8 showed higher cytotoxicity than the corresponding liposomes. Thus, SLP and TSLP displayed reduced cytotoxicity as a vector. There was no significant difference in cytotoxicity between SLP and TSLP.

Study of FAM-siRNA uptake by flow cytometry. Flow cytometry was used to quantify the uptake of SLP/siRNA and TSLP/siRNA by HeLa and HepG2 cells (Figure 4). The
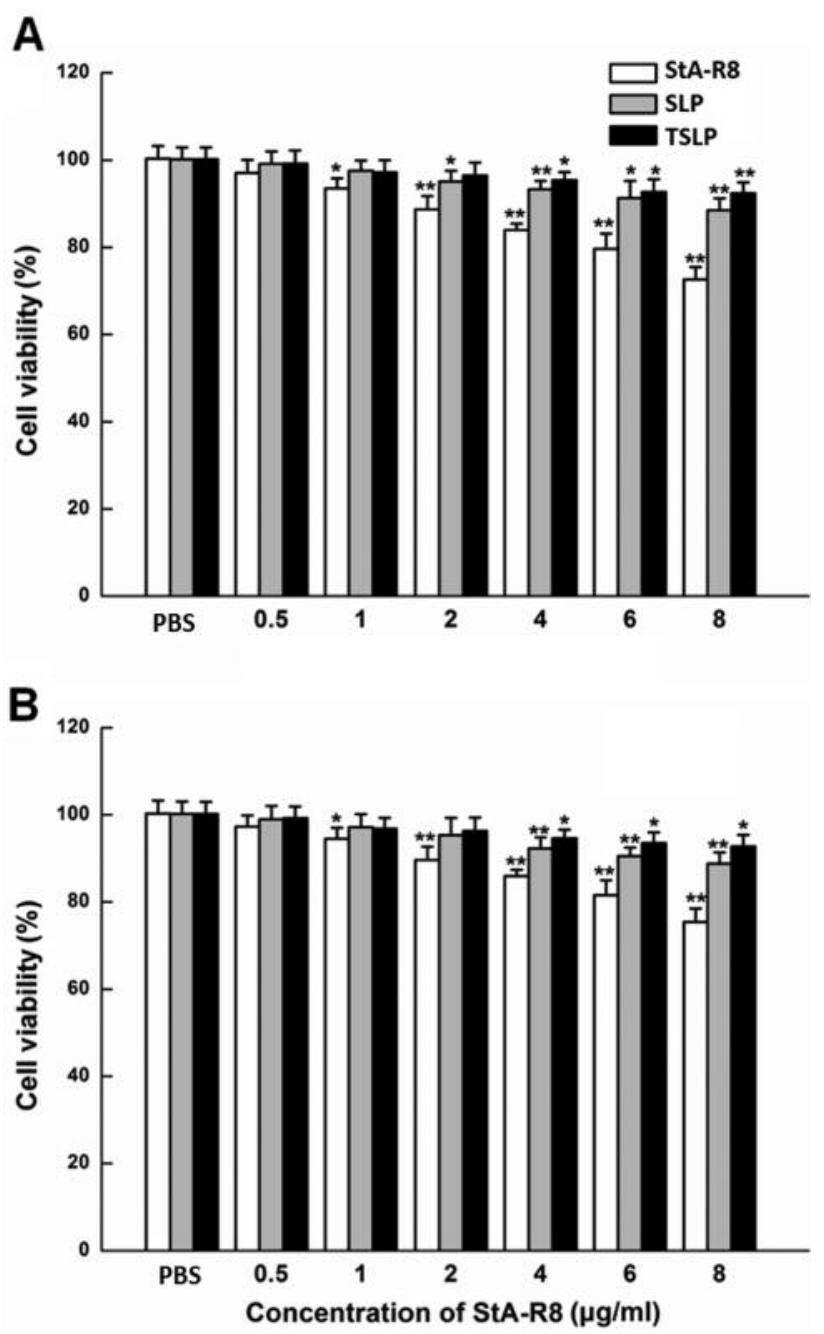

Figure 3. Cytotoxicity of different agents. HeLa (A) and HepG2 (B) cells were treated with PBS (vehicle control), StA-R8, SLP, or TSLP and assessed for viability by the MTT assay, as described in Materials and Methods. ${ }^{*} p<0.05 ; * * p<0.01 ; * * * p<0.001$ compared with untreated control.

fluorescence intensity peaks of cells after treatment with FAM-siRNA liposomes migrated to the right (Figure $4 \mathrm{~A}$ and B). This showed that, compared to naked siRNA, the uptake of SLP/siRNA and TSLP/siRNA by HeLa and HepG2 cells were much higher. The mean fluorescence intensities of the treated cells are shown in Figure $4 \mathrm{C}$ and D. In HeLa cells, the fluorescence intensity values for cells treated with TSLP/siRNA complexes were about 10 times those with naked siRNA. In HepG2 cells, TSLP/siRNA complexes also showed higher cellular uptake. Meanwhile, the uptake efficiency of TSLP/siRNA was higher than that of SLP/siRNA. These data indicate that Tf in TSLP mediated more efficient in vitro uptake of siRNA. 

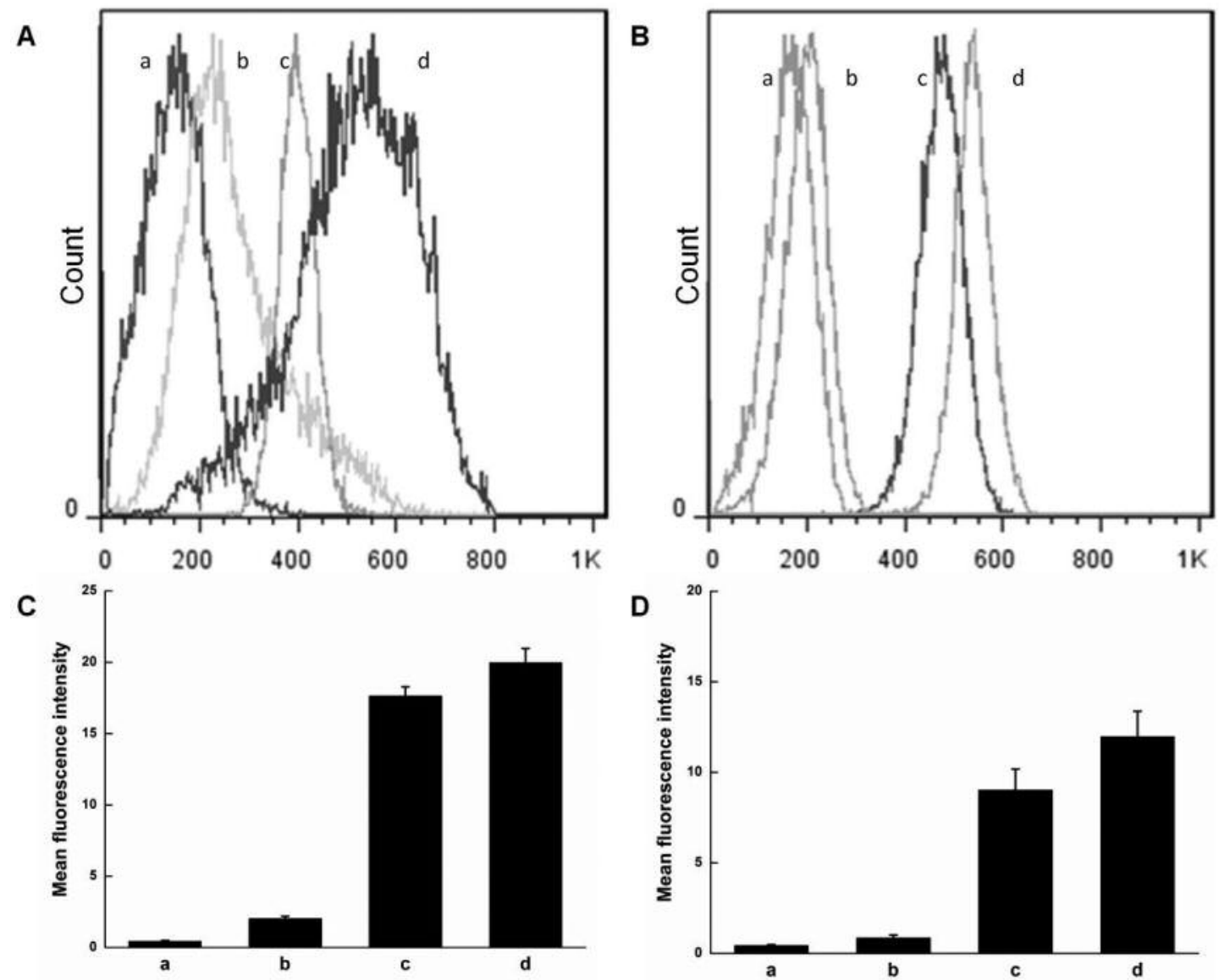

Figure 4. Cellular fluorescence uptake in vitro by flow cytometry. HeLa (A) and HepG2 (B) cells were treated with 6-carboxyfluorescein-labeled siRNA complexed to liposomes and then analyzed by flow cytometry. Mean fluorescence values of HeLa (C) and HepG2 (D) cells are shown. The treatments were: $a$ : Control, $b$ : siRNA, $c$ : stearic acid-modified octa-arginine-containing liposomes/siRNA, d: transferrin-conjugated liposomes containing stearic acid-modified octa-arginine/siRNA.

Cellular internalization analysis by confocal microscopy. The internalization of FAM-labeled siRNA mediated by SLP and TSLP was further evaluated in HeLa cells by confocal microscopy (Figure 5). DAPI was used for labelling the nucleus. Green fluorescence of FAM-siRNA was extensively distributed in the cytosol and the nuclei. In addition, the fluorescence intensity of $\mathrm{HeLa}$ cells treated with TSLP/siRNA complexes was higher than those treated with SLP/siRNA complexes. Confocal microscopy analysis indicated that the association of SLP/siRNA with HeLa cells was greater than that of TSLP/siRNA.

Determination of survivin protein. The expression levels of survivin protein in HeLa cells were determined by western blot. Densitometric analysis was used to calculate the relative level of survivin expression. The SLP/siRNA and SLP/siRNA complexes significantly inhibited the expression of survivin protein in HeLa cells, indicating that these liposomes were able to deliver survivin siRNA into cells and induce RNA interference. The results showed that TSLP/siRNA complexes more efficiently reduced the survivin protein level compared to SLP/siRNA complexes (Figure 6A). Treatment of cells with SLP/siRNA and TSLP/siRNA complexes reduced the expression of survivin protein to $44.1 \%$ and $20.4 \%$ of the control, respectively. The delivery efficiency of siRNA by TSLP was significant higher than SLP in the cell lines tested (Figure 6).

\section{Discussion}

In this study, we investigated liposomes containing StA-R8 and conjugated to Tf for delivery of survivin siRNA. TfPEG-DSPE was inserted into StA-R8- liposomes to further improve siRNA delivery into cancer cells.

Here, we prepared two types of liposomes, SLP and TSLP. After complexing with siRNA, TSLP had increased particle 


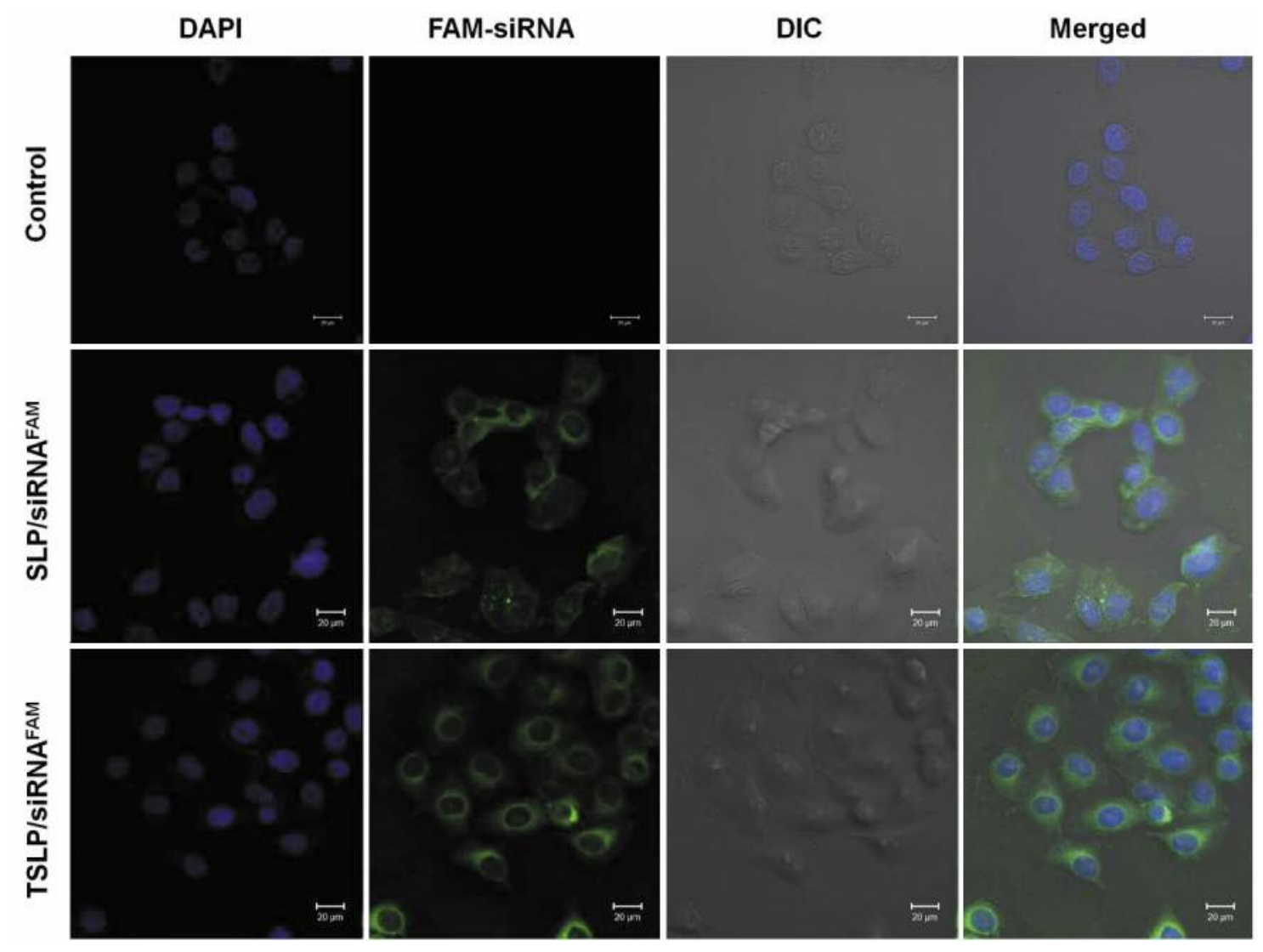

Figure 5. Intracellular localization of siRNA complexes by confocal microscopy. HeLa cells were treated with stearic acid-modified octa-argininecontaining liposomes (SLPS)/siRNA or transferrin-conjugated liposomes containing stearic acid-modified octa-arginine (TSLP)/siRNA complexes, stained and visualized, as described in the Materials and Methods section. Blue color: 4',6-Diamidino-2-phenylindole (DAPI)-stained nuclei, green color: 6-carboxyfluorescein (FAM)-labeled siRNA. DIC: differential interference (phase) contrast bright-field image.

A

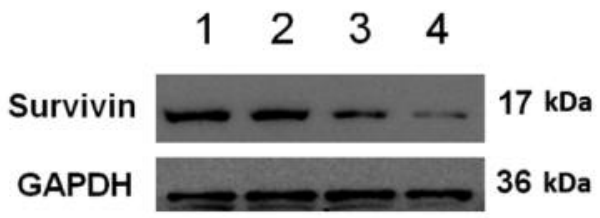

B

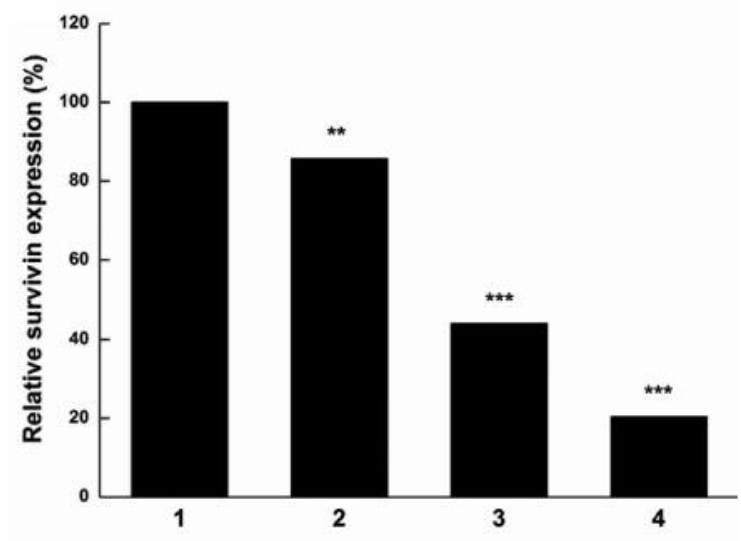

Figure 6. Effect on siRNA on survivin protein expression in HeLa cells. Survivin expression is shown by western blot (A) and by densitometric analysis (B). Lane 1, control; lane 2, siRNA; lane 3, stearic acid-modified octa-arginine (StA-R8)-containing liposome/siRNA complexes; lane 4, transferrin-conjugated liposomes containing StA-R8/siRNA complexes. Data are the mean and standard deviation of three experiments. $* * p<0.01$, $* * * p<0.001$ vs. control. 
size and decreased $\zeta$-potential compared to SLP (Table I). The colloidal stability of TSLP at $4^{\circ} \mathrm{C}$ was excellent. At the same time, incorporation of StA-R8 into liposomes apparently reduced their cytotoxicity (Figure 3). Tfconjugated StA-R8 liposomes increased cellular delivery of survivin siRNA in vitro, as shown by increased siRNA uptake by tumor cells (Figures 4 and 5) and greater downregulation of survivin (Figure 6). This is likely due to active targeting of $\mathrm{Tf}$ receptors.

TSLP has reduced cytotoxicity and improved delivery efficiency for siRNA, and therefore warrants further evaluation as a siRNA delivery vehicle.

\section{References}

1 Lindgren $\mathrm{M}$ and Langel $\mathrm{U}$ : Classes and prediction of cellpenetrating peptides. Meth Mol Biol 683: 3-19, 2011.

2 Stewart KM, Horton KL and Kelley SO: Cell-penetrating peptides as delivery vehicles for biology and medicine. Org Biomol Chem 6: 2242-2255, 2008.

3 Jones AT and Sayers EJ: Cell entry of cell-penetrating peptides: tales of tails wagging dogs. J Control Release 161: 582-591, 2012.

4 Vives E, Brodin P and Lebleu B: A truncated HIV-1 Tat protein basic domain rapidly translocates through the plasma membrane and accumulates in the cell nucleus. J Biol Chem 272: 1601016017, 1997.

5 Derossi D, Joliot AH, Chassaing G and Prochiantz A: The third helix of the Antennapedia homeodomain translocates through biological membranes. J Biol Chem 269: 10444-10450, 1994

6 Pooga M, Hallbrink M, Zorko M and Langel U: Cell penetration by transportan. FASEB J 12: 67-77, 1998.

7 Rothbard JB, Garlington S, Lin Q, Kirschberg T, Kreider E, McGrane PL, Wender PA and Khavari PA: Conjugation of arginine oligomers to cyclosporin A facilitates topical delivery and inhibition of inflammation. Nat Med 6: 1253-1257, 2000.

8 Lattig-Tunnemann G, Prinz M, Hoffmann D, Behlke J, PalmApergi C, Morano I, Herce HD and Cardoso MC: Backbone rigidity and static presentation of guanidinium groups increases cellular uptake of arginine-rich cell-penetrating peptides. Nat Commun 2: 6, 2011.

9 Elsabahy M, Nazarali A and Foldvari M: Non-viral nucleic acid delivery: key challenges and future directions. Curr Drug Deliv 8: 235-244, 2011.

10 Gao Y, Liu XL and Li XR: Research progress on siRNA delivery with nonviral carriers. Int J Nanomed 6: 1017-1025, 2011.

11 Campani V, De Rosa G, Misso G, Zarone MR and Grimaldi A: Lipid nanoparticles to deliver miRNA in Cancer. Curr Pharm Biotechnol 17: 741-749, 2016.

12 Xie J, Yang Z, Zhou C, Zhu J, Lee RJ and Teng L: Nanotechnology for the delivery of phytochemicals in cancer therapy. Biotechnol Adv 34: 343-353, 2016.

13 Halama A, Kulinski M, Librowski T and Lochynski S: Polymerbased non-viral gene delivery as a concept for the treatment of cancer. Pharmacol Rep 61: 993-999, 2009.
14 Lee SK, Siefert A, Beloor J, Fahmy TM and Kumar P: Cellspecific siRNA delivery by peptides and antibodies. In: Methods In Enzymology, Vol 502: Protein Engineering for Therapeutics, Pt A. Wittrup KD and Verdine GL (eds.). San Diego: Elsevier Academic Press Inc, pp. 91-122, 2012.

15 Torchilin VP, Rammohan R, Weissig V and Levchenko TS: TAT peptide on the surface of liposomes affords their efficient intracellular delivery even at low temperature and in the presence of metabolic inhibitors. Proc Natl Acad Sci USA 98: 8786-8791, 2001.

16 Khalil IA, Kogure K, Futaki S and Harashima H: High density of octaarginine stimulates macropinocytosis leading to efficient intracellular trafficking for gene expression. J Biol Chem 281: 3544-3551, 2006.

$17 \mathrm{Li} \mathrm{YH,} \mathrm{Lee} \mathrm{RJ,} \mathrm{Yu} \mathrm{KT,} \mathrm{Bi} \mathrm{Y,} \mathrm{Qi} \mathrm{YH,} \mathrm{Sun} \mathrm{YT,} \mathrm{Li} \mathrm{YJ,} \mathrm{Xie} \mathrm{J} \mathrm{and}$ Teng LS: Delivery of siRNA using lipid nanoparticles modified with cell penetrating peptide. ACS Appl Mater Inter 8: 2661326621, 2016.

18 Daniels TR, Delgado T, Rodriguez JA, Helguera G and Penichet ML: The transferrin receptor part I: Biology and targeting with cytotoxic antibodies for the treatment of cancer. Clin Immunol 121: 144-158, 2006.

19 Daniels TR, Delgado T, Helguera G and Penichet ML: The transferrin receptor part II: Targeted delivery of therapeutic agents into cancer cells. Clin Immunol 121: 159-176, 2006.

20 Tortorella S and Karagiannis TC: Transferrin receptor-mediated endocytosis: a useful target for cancer therapy. J Membr Biol 247: 291-307, 2014.

21 Futaki S, Suzuki T, Ohashi W, Yagami T, Tanaka S, Ueda K and Sugiura Y: Arginine-rich peptides - An abundant source of membrane-permeable peptides having potential as carriers for intracellular protein delivery. J Biol Chem 276: 5836-5840, 2001.

22 Yang DS, Li YH, Qi YH, Chen YZ, Yang XW, Li YJ, Liu SC and Lee RJ: Delivery of siRNA using cationic liposomes incorporating stearic acid-modified octa-arginine. Anticancer Res 36: 3271-3276, 2016.

23 Yang ZG, Yu B, Zhu J, Huang XM, Xie J, Xu SL, Yang XJ, Wang XM, Yung BC, Lee LJ, Lee RJ and Teng LS: A microfluidic method to synthesize transferrin-lipid nanoparticles loaded with siRNA LOR-1284 for therapy of acute myeloid leukemia. Nanoscale 6: 9742-9751, 2014.

24 Chiu SJ, Liu SJ, Perrotti D, Marcucci G and Lee RJ: Efficient delivery of a BCL-2-specific antisense oligodeoxyribonucleotide (G3139) via transferrin receptor-targeted liposomes. J Control Release 112: 199-207, 2006.

25 Yang XW, Yang S, Chai HY, Yang ZG, Lee RJ, Liao WW and Teng LS: A novel isoquinoline derivative anticancer agent and its targeted delivery to tumor cells using transferrin-conjugated liposomes. PLoS One 10: 12, 2015. 